\title{
Níveis de proteína em suplementos para novilhos mestiços em pastejo durante o período de transição seca/águas
}

\author{
Eduardo Henrique Bevitori Kling de Moraes $^{2}$, Mário Fonseca Paulino ${ }^{3}$, Joanis Tilemahos \\ Zervoudakis ${ }^{4}$, Edenio Detmann ${ }^{3}$, Sebastião de Campos Valadares Filho ${ }^{3}$, Rilene Ferreira \\ Diniz Valadares ${ }^{5}$, Kamila Andreatta Kling de Moraes $^{6}$
}

\footnotetext{
1 Parte da dissertação de Mestrado do primeiro autor.

2 Doutorando, Bolsista CNPq, DZO/UFV.

${ }^{3}$ DZO-UFV, Viçosa-MG, 36570-000, Bolsista do CNPq.

${ }^{4}$ DPA/UFMT, Cuiabá-MT, 78060-900.

${ }^{5}$ DVT-UFV, Viçosa-MG, 36570-000, Bolsista do CNPq.

${ }^{6}$ Mestranda, DZO-UFV, Viçosa-MG, 36570-000. Bolsista da CAPES.
}

RESUMO - Dois experimentos foram realizados com o objetivo de avaliar níveis de PB em suplementos para novilhos mestiços em pastagem dePanicum maximum cv. Mombaça durante o período de transição seca/águas. Os suplementos, à base de milho e grão de soja triturados, foram formulados para apresentar 8,0; 16,0 e 24,0\% de PB e foram fornecidos na quantidade de 1,0 kg/dia. No primeiro experimento, foram avaliados o desempenho produtivo e a eficiência econômica de 20 novilhos mestiços Holandês x Zebu, não-castrados, com 19 meses de idade e 339,4ะ14,8 kg de PV inicial. O ganho médio diário e o ganho de peso total aumentaram de forma linear de acordo com os níveis de proteína nos suplementos. Os ganhos observados foram de 0,$992 ; 1,142$ e 1,261 kg/dia, respectivamente, para os suplementos com 8,0;16,0 e 24,0\% de PB. A avaliação econômica dos suplementos comprovou maior eficiência econômica do suplemento com $24 \%$ de PB. No segundo experimento, quatro novilhos mestiços (peso médio de $400 \mathrm{~kg}$ ) fistulados no rúmen e no esôfago foram utilizados para avaliar a influência dos níveis de proteína sobre o pH e a concentração de amônia ruminal. $\mathrm{O}$ pH não foi alterado, mas a concentração ruminal de $\mathrm{N}-\mathrm{NH}_{3}$ aumentou de forma linear com os níveis de proteína do suplemento. Os níveis amoniacais médios observados com os suplementos contendo 8,$0 ; 16,0$ e $24,0 \%$ de PB foram de 8,$41 ; 10,69$ e $12,92 \mathrm{mg} / \mathrm{dL}$, respectivamente.

Palavras-chave: amônia ruminal, análise de sensibilidade, $\mathrm{pH}$, suplementação protéica

\section{Feeding supplements with different crude protein levels to dairy crossbreed steers on pasture during the transition period between the dry and rainy season}

\begin{abstract}
Two experiments were conducted to evaluate different crude protein (CP) levels of a mixture of mineral and concentrate (multiple supplement) fed to crossbreed steers grazing Panicum maximum cv. Mombaça pasture during the transition between the dry and the rainy season. The multiple supplement contained ground corn and soybean grains and was formulated to yield $8.0,16.0$ or $24.0 \%$ of $\mathrm{CP}$. Each animal received $1.0 \mathrm{~kg}$ of the multiple supplement per day or only ad libitum mineral mix (control treatment). In the first trial, 20 crossbred steers averaging 19 months of age and $339.4 \pm 14.8 \mathrm{~kg}$ of body weight were used. The average daily gain (ADG) increased linearly from 0.992 to $1.258 \mathrm{~kg} / \mathrm{d}$ when the CP level of the supplement increased from 8.0 to $24 \%$. Total weight gain also increased linearly by increasing the CP level of the supplement. Economical analysis of the supplements showed greater gross income for the supplement containing $24 \%$ $\mathrm{CP}$. In the second trial, four crossbreed steers fitted with ruminal and esophageal cannulas and averaging $400 \mathrm{~kg}$ of body weight were used to investigate different $\mathrm{CP}$ levels of the supplements on ruminal $\mathrm{pH}$ and ruminal ammonia ruminal concentration. The different $\mathrm{CP}$ levels of the supplement did not significantly change ruminal pH. However, ruminal ammonia increased linearly from 8.41 to $12.2 \mathrm{mg} / \mathrm{dL}$ when the CP level of the supplement increased from 8.0 to $24 \%$.
\end{abstract}

Key Words: pH, protein supplementation, ruminal ammonia, sensitivity analysis

\section{Introdução}

Nos sistemas de produção de carne bovina no Brasil, normalmente as pastagens são utilizadas como substrato básico, constituindo 99\% da dieta dos animais (Paulino et al., 2003). Nestes sistemas, no final da seca e início da estação das chuvas (transição seca/águas), observa-se o aparecimento de rebrotações nas pastagens. Segundo Detmann et al. (2005b), como consequiência dos níveis elevados de compostos nitrogenados não-protéicos e/ou 
dos níveis reduzidos de energia de rápida disponibilidade ruminal, observa-se baixo aproveitamento dos compostos nitrogenados, como resultado de sua baixa fixação em proteína microbiana.

Por outro lado, ocorre mobilização de $\mathrm{N}$ na forma de proteínas solúveis para formas insolúveis associadas à parede celular, de baixa disponibilidade aos animais (Paulino et al., 2003). Animais em pastejo nestas condições podem responder ao aumento no fornecimento de proteína (Moraes et al., 2005), que pode ser obtido de forma direta, com utilização de suplementos protéicos, ou indireta, pela utilização de suplementos energéticos, os quais ampliam a síntese de compostos nitrogenados microbianos a partir do $\mathrm{N}$ da forragem.

A suplementação com apenas fontes energéticas, no entanto, não eliminaria as deficiências energéticas e protéicas, pois não atende de forma satisfatória às exigências protéicas dos animais (Paulino et al., 1982). Por outro lado, tanto a deficiência de energia quanto a de proteína podem ser eliminadas somente com a correção da deficiência protéica.

Segundo Reis et al. (2005), tem sido grande a preocupação em promover o ajuste no sistema de produção em pastagem por meio da suplementação. Neste contexto, verifica-se o uso de suplementação no período de transição seca/águas como opção para o suprimento de nutrientes limitantes e o aumento da eficiência de utilização das pastagens, permitindo maior produção, com possíveis retornos econômicos.

Durante o ano, existe uma estação mais seca na qual o baixo teor de proteína é fator limitante. Grande parte das pesquisas concentra informações sobre a suplementação protéica neste período. No entanto, são poucas são as informações sobre a suplementação protéica para bovinos em terminação durante o período de transição seca/águas.

Ainda que as deficiências nutricionais em ambos os períodos estejam relacionadas à proteína, a mudança da estação seca para a chuvosa altera o enfoque sobre esta deficiência, transformando-a de dietética para metabólica (Detmann et al., 2005a).

Considerando que o grande entrave na utilização de suplementos protéicos na chegada do período chuvoso consiste na determinação dos níveis de inclusão na dieta (McCollum III \& Horn, 1989), avaliaram-se os efeitos da suplementação com diferentes níveis de PB sobre o desempenho produtivo, a eficiência econômica e os parâmetros ruminais de novilhos mestiços em pastagens de capimmombaça no período de transição seca/águas.

\section{Material e Métodos}

Dois experimentos foram realizados em Capinópolis MG, na Central de Experimentação, Pesquisa e Extensão do Triângulo Mineiro - CEPET, da Universidade Federal de Viçosa, durante o período de transição seca/águas, entre os meses de outubro e dezembro de 2001.

No primeiro experimento, utilizaram-se 20 novilhos mestiços não-castrados Holandês x Zebu, com 19 meses de idade e peso inicial de $339,4 \pm 14,8 \mathrm{~kg}$.

A área experimental destinada aos animais foi constituída de quatro piquetes (1,0 ha) dePanicum maximumcv. Mombaça, providos de bebedouro e comedouro ( $2 \mathrm{~m}$ de comprimento) com acesso dos dois lados, permitindo a alimentação de todos os animais simultaneamente.

Os suplementos utilizados, à base de milho e grão de soja triturados, foram formulados para apresentar 8,0;16,0 e $24,0 \%$ de PB, sendo fornecidos diariamente, em oferta única (às $10 \mathrm{~h}$ em comedouro conjunto), na quantidade de $1,0 \mathrm{~kg} / \mathrm{animal} / \mathrm{dia}$, em comparação a um tratamento controle com mistura mineral fornecida à vontade (Tabela 1). Ressalta-se que o tratamento com $8,0 \%$ de PB foi constituído apenas por milho e mistura mineral, sendo, portanto, um suplemento de natureza energética.

Visando reduzir a influência da possível variação na disponibilidade de MS entre os piquetes, os animais foram mantidos em cada piquete por sete dias e, após este período, foram rotacionados, mantendo-se os mesmos tratamentos, em sentido pré-estabelecido.

Os animais foram pesados ao início do período experimental e, a partir desta data, a cada 28 dias. O ganho de peso total foi estimado pela diferença entre os pesos final e

Tabela 1 - Composição dos suplementos (\%), com base na matéria natural

Table 1 - Ingredient composition of the supplements, as-fed basis (\%)

\begin{tabular}{lcccc}
\hline $\begin{array}{l}\text { Ingrediente (\%) } \\
\text { Ingredient }\end{array}$ & \multicolumn{4}{c}{$\begin{array}{c}\text { Nível de proteína (\%) } \\
\text { Protein level }\end{array}$} \\
\cline { 2 - 5 } & MM* & 8 & 16 & 24 \\
\hline $\begin{array}{l}\text { Mistura mineral } \\
\text { Mineral mix }\end{array}$ & 100,0 & 5,0 & 5,0 & 5,0 \\
$\begin{array}{l}\text { Grão de soja triturado } \\
\text { Ground soybean grain } \\
\text { Grão de milho triturado } \\
\text { Ground corn grain }\end{array}$ & - & - & 30,0 & 60,0 \\
\hline
\end{tabular}

1 Composição percentual (percentage composition): cloreto de sódio (sodium chloride): 50,0; fosfato bicálcico (dicalcium phosphate): 47,64 ; sulfato de zinco (zinc sulfate): 1,50; sulfato de cobre (copper sulfate): 0,75 ; sulfato de cobalto (cobalt sulfate): 0,05; iodato de potássio (potassium iodate): 0,06.

* Mistura mineral (mineral mix). 
inicial, após jejum alimentar e hídrico (18 horas). Ao final do período experimental, os animais foram abatidos para avaliação do peso da carcaça para posterior cômputo do rendimento de carcaça.

Realizaram-se coletas de amostras da pastagem, nos diferentes piquetes, a cada 15 dias por meio do corte, a 10 $\mathrm{cm}$ do nível do solo, de cinco áreas delimitadas por um quadrado metálico $(0,5 \times 0,5 \mathrm{~m})$. Após a pesagem, cada amostra foi pesada e homogeneizada, sendo retiradas duas alíquotas compostas, uma para avaliação da disponibilidade total de MS/ha (MST) e outra para análise da disponibilidade total de matéria seca verde/ha (MSV) em cada piquete experimental.

As amostras da pastagem e dos suplementos foram submetidas a análises laboratoriais para determinação dos teores de MS, PB, proteína insolúvel em detergente neutro (PIDN), proteína insolúvel em detergente ácido (PIDA), cinzas, EE, CT, FDN, FDA, CNF e lignina, de acordo com recomendações de Silva \& Queiroz (2002). As avaliações dos teores de FDN e FDA seguiram os métodos de Mertens (2002) e Van Soest \& Robertson (1985), respectivamente. Os CNF foram calculados de acordo com Weiss (1999), como: $\mathrm{CNF}(\%)=[100-(\% \mathrm{FDN}+\% \mathrm{~PB}+\% \mathrm{EE}+\% \mathrm{CIN})]$. Os $\mathrm{CT}$, no entanto, foram calculados de acordo com Sniffen et al. (1992), pela fórmula: CT $(\% \mathrm{MS})=100-[\mathrm{PB}(\% \mathrm{MS})+\mathrm{EE}$ $(\% \mathrm{MS})+\operatorname{cinzas}(\% \mathrm{MS})]$.

A avaliação econômica do desempenho animal foi realizada com base na orçamentação parcial, considerando as receitas e despesas adicionais em relação ao tratamento controle (mistura mineral). Para melhor visualização dos resultados, efetuou-se análise de sensibilidade em relação à possível diferenciação de preço de suplementos e venda dos animais, isto é, qual seria o impacto econômico em um sistema de suplementação que passasse a produzir novilho precoce e receber, como benefício adicional, melhor preço pela qualidade dos animais produzidos. Ressalta-se que todas as cotações foram tomadas na região e no período em que o experimento foi realizado.

As análises referentes ao desempenho dos animais foram conduzidas em delineamento inteiramente casualizado e as comparações entre as médias observadas foram realizadas por meio da decomposição da soma de quadrados para tratamentos em contrastes ortogonais relativos à comparação entre suplementação e não-suplementação e aos efeitos de ordens linear e quadrática em função dos níveis de proteína nos suplementos com posteriores ajuste de equações de regressão linear. Adotou-se $\alpha=0,10$.

No segundo experimento, para análise dos parâmetros ruminais, utilizaram-se quatro bovinos Holandês x Zebu, fistulados no rúmen e esôfago, distribuídos em delinea- mento quadrado latino (4 x 4), para avaliação da forragem ingerida e dos parâmetros ruminais ( $\mathrm{pH}$ e concentração de amônia). O experimento foi realizado simultaneamente ao primeiro (análise do desempenho) e foi composto por quatro períodos de dez dias, nos quais os sete primeiros dias foram destinados à adaptação dos animais. Os animais receberam os mesmos suplementos fornecidos no experimento de desempenho.

A área experimental destinada aos novilhos fistulados era contígua aos piquetes dos animais de desempenho e composta de quatro piquetes $(0,5 \mathrm{ha})$ de Panicum maximum cv. Mombaça, providos de bebedouro e comedouro cobertos.

Para avaliação da forragem ingerida pelos animais, amostras da extrusa esofágica foram coletadas no quinto dia de cada período experimental e, posteriormente, formaram uma única amostra por período. Os animais foram mantidos em jejum por 12 horas no dia anterior à coleta com o objetivo de evitar possível regurgitação ou contaminação da amostra (McMeniman, 1997).

Após o período de adaptação aos tratamentos aplicados, realizou-se a coleta de amostras de líquido ruminal para determinação do $\mathrm{pH}$ e da concentração de amônia 4 horas após o fornecimento do suplemento (14h). As amostras foram filtradas em gaze para eliminação das partículas maiores. As análises de $\mathrm{pH}$ foram realizadas imediatamente após a coleta utilizando-se peagâmetro digital. Para determinação de amônia, separou-se uma alíquota de $50 \mathrm{~mL}$, que foi fixada com 1,0 mL de $\mathrm{H}_{2} \mathrm{SO}_{4}$ (1:1), sendo acondicionada em recipiente de plástico, identificada e congelada a $-20^{\circ} \mathrm{C}$.

As análises referentes aos animais fistulados foram realizadas em delineamento em quadrado latino ( 4 x 4), com quatro tratamentos e quatro períodos experimentais. As comparações entre médias foram realizadas por meio da decomposição da soma de quadrados para tratamentos em contrastes ortogonais relativos à comparação entre suplementação e não-suplementação e aos efeitos de ordens linear e quadrática, em função dos níveis de proteína nos suplementos, com posterior ajuste de equações de regressão linear. Adotou-se $\alpha=0,10$.

\section{Resultados e Discussão}

A composição química do capim-mombaça e dos suplementos utilizados no experimento 1 é apresentada na Tabela 2. A forragem disponível, coletada via extrusa, apresentou valor médio de $14,8 \%$ de $\mathrm{PB}$, que foi superior ao limite de $7,0 \%$ de $\mathrm{PB}$, considerado limite mínimo para não comprometer a atividade da microbiota ruminal (Minson, 1990) e o desempenho animal. 
Deve-se, no entanto, considerar a possibilidade de contaminação pelo $\mathrm{N}$ salivar nas amostras da pastagem. Entretanto, segundo Poppi \& McLennan (1995), grande parte deste $\mathrm{N}$ pode ser atribuída à contribuição do NNP da própria forragem, o que é característico em gramíneas tropicais em períodos imediatamente posteriores à ocorrência de chuvas. Por outro lado, Moraes et al. (2005) destacaram que, além da contaminação pelo $\mathrm{N}$ salivar, deve-se considerar a capacidade dos animais em selecionar uma dieta de melhor qualidade.

As disponibilidades estimadas de MST e MSV da pastagem de Panicum maximum cv Mombaça durante o período experimental foram, respectivamente, 6.453 e $4.953 \mathrm{~kg} / \mathrm{ha}$ (Figura 1). Em períodos longos de ocupação da pastagem, ocorrem redução na disponibilidade de forragem e mudanças na estrutura das plantas, principalmente na proporção folha/colmo, que podem afetar de forma severa o comportamento ingestivo e, conseqüentemente, a produção animal.

No entanto, a oferta média de forragem, expressa em quilos de MS por unidade animal (kg MS/UA), durante o período experimental, apresentou valores de 8 a $11 \%$, considerados por Barbosa et al. (2001) necessários para garantir consumo máximo de forragem, menor tempo de pastejo e maior quantidade de forragem degradada no rúmen. Dessa

Tabela 2 - Teores médios de MS (MS\%), PB, proteína insolúvel em detergente neutro (PIDN), proteína insolúvel em detergente ácido (PIDA), cinzas, EE, carboidratos totais (CT), FDN, CNF, FDA e lignina do capim-mombaça e dos suplementos

Table 2 - Average contents of DM (DM\%), CP, neutral detergent insoluble protein (NDIP), acid detergent insoluble protein (ADIP), ash, $E E, T C, N D F, N F C, A D F$, and lignin of mombaçagrass and supplements

\begin{tabular}{|c|c|c|c|c|c|}
\hline \multirow[t]{2}{*}{ Item } & \multicolumn{4}{|c|}{$\begin{array}{c}\text { Nível de proteína }(\%) \\
\text { Protein level }\end{array}$} & \multirow[b]{2}{*}{$\begin{array}{c}\text { Mombaça }{ }^{1} \\
\text { Mombaçagrass }\end{array}$} \\
\hline & $\mathrm{MM}^{*}$ & 8 & 16 & 24 & \\
\hline $\mathrm{MS}(D M), \%$ & 98,0 & 88,9 & 89,7 & 90,5 & 12,8 \\
\hline $\mathrm{PB}(C P)$ & - & 8,5 & 16,5 & 24,5 & 14,3 \\
\hline $\mathrm{PIDN}^{2}(N D I P)$ & - & 8,0 & 9,2 & 10,4 & 35,9 \\
\hline $\mathrm{PIDA}^{2}(A D I P)$ & - & 6,0 & 5,5 & 5,0 & 9,6 \\
\hline CIN (Ash) & - & 4,2 & 8,9 & 13,7 & 1,4 \\
\hline $\mathrm{EE}$ & - & 1,9 & 2,9 & 4,0 & 1,3 \\
\hline $\mathrm{CT}^{3}(T C)$ & - & 85,4 & 71,7 & 57,8 & 71,3 \\
\hline $\mathrm{FDN}(N D F)$ & - & 14,3 & 15,5 & 16,7 & 66,3 \\
\hline $\mathrm{CNF}^{4}(N F C)$ & - & 71,1 & 56,2 & 41,1 & 16,7 \\
\hline FDA $(A D F)$ & - & 3,0 & 6,4 & 9,8 & 38,2 \\
\hline Lignina (Lignin) & - & 1,0 & 2,2 & 3,3 & 6,2 \\
\hline
\end{tabular}

${ }^{1}$ Extrusa coletada nos animais fistulados; $2 \%$ Proteína total; ${ }^{3} \mathrm{CT}=100$ (PB+EE+Cinzas); ${ }^{4} \mathrm{CNF}=100-(\mathrm{FDN}+\mathrm{PB}+\mathrm{EE}+\mathrm{Cinzas})$.

${ }^{1} \%$ DM; ${ }^{2}$ Extrusa collected from the fistulated animals; ${ }^{3} \%$ Total protein; ${ }^{4} T C=100$ $(C P+E E+A s h), 5 F C=100-(N D F+C P+E E+A s h)$.

* Mistura mineral (mineral mix). forma, os valores observados permitem inferir sobre a inexistência de entraves sobrea seletividade, garantindoa possibilidade de maximização do consumo de MS da forragem disponível.

Os valores referentes ao peso vivo em jejum inicial (PVJI) e final (PVJF), ao ganho médio diário (GMD), ao peso (PC) e ao rendimento de caraça (RC) dos animais para os diferentes tratamentos são apresentados na Tabela 3.

A boa qualidade da pastagem disponível para os animais propiciou bom desempenho aos animais do tratamento controle (mistura mineral). Embora não tenham sido observadas diferenças entre os animais dos tratamentos com e sem suplementação $(\mathrm{P}>0,10)$, a análise apontou aumento linear $(\mathrm{P}<0,10)$ do desempenho produtivo dos animais com o aumento do nível de proteína dos suplementos. A ausência de diferenças entre o fornecimento ou não de suplementos, apesar do efeito dos níveis de proteína, deve-se à estrutura do contraste empregado, o qual compara a média de animais sem e com suplementação à média geral de todos os suplementos, o que pode ter tornado estes valores equivalentes.

Animais consumindo suplementos energéticos apresentaram desempenho praticamente equivalente ao daqueles que receberam apenas mistura mineral. Este comportamento indica que, de fato, o fornecimento exclusivo de suplementos energéticos não propicia aporte de $\mathrm{N}$ necessário para potencializar o desempenho de animais em regime de pastejo durante as águas. No entanto, ressalta-se que a fonte energética utilizada (milho) possui proteína de baixa qualidade, seja pela resistência à degradação seja pela baixa qualidade de seu perfil de aminoácidos. Assim, mais estudos devem ser desenvolvidos para avaliação do efeito da utilização de outras fontes de energia com maior teor protéico

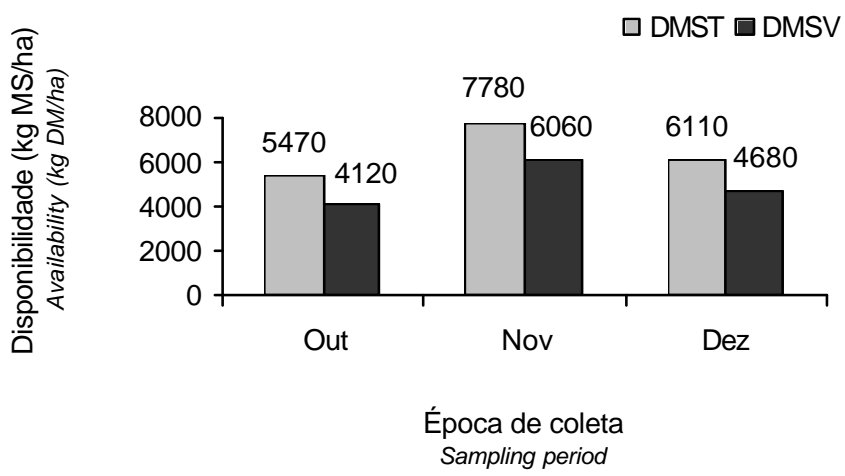

Figura 1 - Disponibilidade média de MS total (DMST) e de matéria seca verde (DMSV) do capim-mombaça nos diferentes períodos de coleta.

Figure 1 - Average availability of total DM (DMST) and green DM (DMSV) of Mombaça pasture in different sampling periods. 
e melhor perfil de aminoácidos que o milho na formulação de suplementos energéticos.

Embora não se tenha observado diferença $(\mathrm{P}>0,10)$, quando comparado ao tratamento controle (mistura mineral), o suplemento com maior nível protéico promoveu aumentos de 4,13 no PVJF e 18,40\% no GMD dos animais, o que poderia ser explicado pela necessidade de balanceamento e/ou pelo sincronismo adequado entre a matéria orgânica fermentável no rúmen e a utilização de nitrogênio pelos microrganismos ruminais para melhor síntese de proteína microbiana e maior disponibilidade de aminoácidos para absorção no intestino delgado (Sniffen et al., 1992). Este suplemento apresentou proteína verdadeira proveniente do grão de soja na composição, conferindo tempos e taxas de degradação protéica adequadas para o crescimento microbiano, além de certo aporte energético adicional, o que não ocorreu com o tratamento com mistura mineral.

Utilizando a equação de mínimos quadrados (Tabela 3), verificou-se que, quando comparado ao suplemento de natureza energética (8,0\% PB), o suplemento com $24,0 \%$ de $\mathrm{PB}$ propiciou incremento de $0,261 \mathrm{~kg} /$ dia no ganho de peso, que pode estar associado à eliminação dos efeitos associativos negativos entre forragem e grãos, proporcionados pelo atendimento total das exigências de proteína degradada no rúmen (Paulino et al., 2005). Por outro lado, esse aumento pode ser explicado pelo maior consumo de proteína e pelas maiores proporções de amônia ruminal (Tabela 7), os quais propiciariam maior digestão da forragem pelos microrganismos, favorecendo o consumo de forragem pelos animais.

Segundo Chase Jr. \& Hibberd (1987), suplementos à base de milho com inadequada disponibilidade de proteína parecem reduzir o consumo. A redução no consumo de forragem causada pelos suplementos energéticos está as sociada à progressiva diminuição no tempo de pastejo, na taxa e no tamanho de bocado à medida que o nível de suplementos aumentou (Minson, 1990).

Desta forma, suplementos contendo apenas milho devem ser cuidadosamente formulados, pois o fornecimento adicional de proteína degradável no rúmen reduz seus efeitos deletérios, potencializando a utilização de forragem (Zervoudakis et al., 2002a) e, conseqüentemente, o desempenho de bovinos em pastejo durante o período de transição seca/águas.

A avaliação dos indicadores econômicos de produção animal, em termos diários, demonstrou retorno positivo, mesmo que de baixa magnitude, apenas para o suplemento contendo $24 \%$ de PB (Tabela 4). Por outro lado, o suplemento energético ( $8 \%$ ) apresentou os menores indicadores, de modo que o menor ganho diário foi atribuído a esse suplemento.

Foram observadas diferenças quanto ao DPA, que reduziu sensivelmente à medida que se elevou o nível de proteína nos suplementos (Tabela 5). O suplemento com $24 \%$ de PB propiciou maior redução de ocupação da pastagem tanto em dias quanto em $\mathrm{R} \$$ /animal, com melhor retorno econômico considerando o beneficio de desocupação de pastagem pela antecipação do abate. Ressalta-se que, mesmo considerando os efeitos de redução da idade de abate, o fornecimento de suplementos contendo 8 e $16 \%$ de PB não possibilitou retornos econômicos favoráveis.

A suplementação tem sido aplicada no período da seca, promovendo o abate dos animais ainda no período de entressafra. Entretanto, considerando que o adiantamento de capital e a liberação de áreas de pastagem são vantagens diretas quando se reduz a idade ao abate dos animais (El-Memari Neto et al., 2003), pode-se afirmar que o forne-

Tabela 3 - Médias, coeficientes de variação (CV) e probabilidades (P) para peso vivo em jejum, peso vivo inicial (PVJI - kg) e final (PVJF - kg), ganho médio diário (GMD - kg/dia), peso (PC - kg) e rendimento de carcaça (RC\%) para os diferentes níveis de proteína Table 3 - Means, coefficients of variation (CV) and probabilities (P) for initial and final body weight at fasting (IBWF - $\mathrm{kg}$ ) and final (FBWF - $\mathrm{kg}$ ), average daily gain (ADG - kg/day), carcass weight ( $C W-\mathrm{kg}$ ) and yield (CY - \%) of crossbreed steers fed supplements with different crude protein levels

\begin{tabular}{|c|c|c|c|c|c|c|c|c|}
\hline \multirow[b]{2}{*}{ Item } & \multirow[b]{2}{*}{$\mathrm{MM}^{*}$} & \multicolumn{3}{|c|}{$\begin{array}{c}\text { Nível de proteína } \\
\text { Protein level }\end{array}$} & \multicolumn{3}{|c|}{$\begin{array}{c}\text { Valor } \mathrm{P}^{1} \\
P \text { value }\end{array}$} & \multirow[b]{2}{*}{ CV (\%) } \\
\hline & & 8,0 & 16,0 & 24,0 & $\begin{array}{l}\text { MM x suplementação } \\
\text { Mineral mix x supplement }\end{array}$ & $\mathrm{L}$ & Q & \\
\hline PVIJ & 336,5 & 342,2 & 340,2 & 340,7 & - & - & - & 4,81 \\
\hline $\mathrm{PVFJ}^{2}$ & 413,4 & 411,6 & 421,6 & 430,5 & 0,1666 & 0,0127 & 0,9208 & 2,14 \\
\hline $\mathrm{GMD}^{3}$ & 1,065 & 0,992 & 1,142 & 1,261 & 0,2580 & 0,0109 & 0,8817 & 10,82 \\
\hline
\end{tabular}

${ }^{1} \mathrm{MM}$ vs suplementos, $\mathrm{L}$ e $\mathrm{Q}=$ efeitos linear e quadrático para níveis de $\mathrm{PB}$ nos suplementos, respectivamente; ${ }^{2} \hat{\mathrm{Y}}=402,33+1,1825 \mathrm{NP}\left(\mathrm{r}^{2}=0,9988\right)$;

${ }^{3} \hat{\mathrm{Y}}=0,08733+0,0163 \mathrm{NP}\left(\mathrm{r}^{2}=0,9976\right)$.

${ }^{1}$ Mineral mix vs supplements, $L$ and $Q=$ linear and quadratic effects for crude protein levels, respectively.

* Mistura mineral (mineral mix). 
Tabela 4 - Indicadores econômicos de produção, por animal, de acordo com os diferentes suplementos, em função do desempenho médio diário

Table 4 - Economic indicators of production per animal according to supplements with different crude protein levels as function of average daily performance

\begin{tabular}{|c|c|c|c|}
\hline \multirow[b]{2}{*}{ Item } & \multicolumn{3}{|c|}{$\begin{array}{c}\text { Nível de proteína }(\%) \\
\text { Protein level }(\%)\end{array}$} \\
\hline & 8 & 16 & 24 \\
\hline Custo do suplemento $(\mathrm{R} \$ / \mathrm{kg})^{1}$ (Supplement cost, $R \$ / \mathrm{kg}$ ) & 0,325 & 0,385 & 0,445 \\
\hline Custo do suplemento ( $\mathrm{R} \$ / \mathrm{dia}$ ) (Supplement cost, $R \$ /$ day) & 0,325 & 0,385 & 0,445 \\
\hline Custo diferencial ( $\mathrm{R} \$ /$ dia) (Differential cost, $R \$ /$ day) & 0,257 & 0,317 & 0,377 \\
\hline Ganho médio diário ( $\mathrm{kg}$ ) (Average daily gain, $\mathrm{kg}$ ) & 0,922 & 1,142 & 1,261 \\
\hline Ganho diferencial (kg/dia) (Differential gain, $\mathrm{kg} /$ dia) & $-0,073$ & 0,077 & 0,196 \\
\hline Ganho diferencial em carcaça ( $\mathrm{R} \$ /$ dia) ${ }^{2}$ (Carcass differential gain, $R \$ /$ day) & $-0,147$ & 0,162 & 0,401 \\
\hline Retorno (R $\$ /$ dia $)^{2}$ (Income, $R \$ /$ day) & $-0,404$ & $-0,155$ & 0,033 \\
\hline
\end{tabular}

1 Valor dos alimentos (R $\$ / \mathrm{kg})$ : milho - 0,30; grão de soja - 0,50; mistura mineral - 0,80; ${ }^{2}$ Considerando o rendimento de carcaça de cada tratamento (R $\left.\$ 59,29 / @\right)$.

${ }^{1}$ Feed cost $(R \$ / \mathrm{kg})$ : corn grain - 0.30; soybean grain - 0.50; mineral salt - 0.80; ${ }^{2}$ Based on carcass dressing of each treatment (R\$59.29/@).

Tabela 5 - Indicadores econômicos de produção, por animal, de acordo com os diferentes suplementos, em função do total necessário com suplementação e ocupação de pastagem para o abate (450 kg PV)

Table 5 - Economic indicators of production per animal according to supplements with different crude protein levels as function of pasture occupation and total supplementation until slaughter $(450 \mathrm{~kg}$ of body weight)

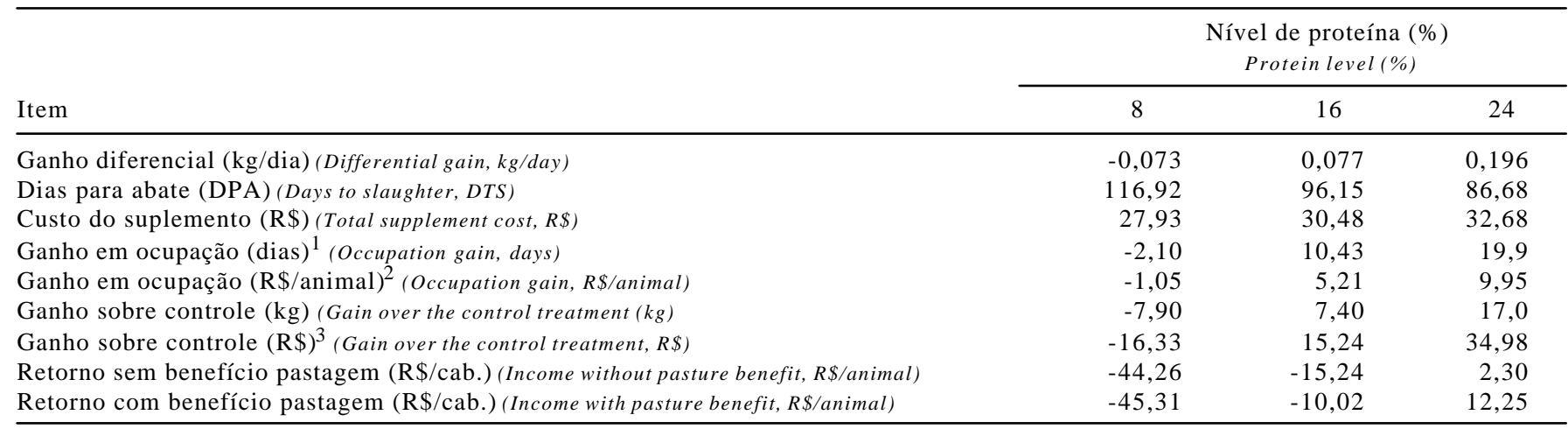

${ }^{1}$ Considerando a mesma média de ganho para o tratamento controle até o abate.

2 Valor comercial de aluguel de pastagem assumido como custo de oportunidade (R\$15,00/cab/mês).

${ }^{3}$ Considerando rendimento de carcaça médio $(52,42 \%)$. Valor de venda: $R \$ 59,29 / @$.

${ }^{1}$ The average daily gain of the control treatment was considered the same until slaughter.

2 Rent value of pasture was assumed as an opportunity cost ( $R \$ 15.00 /$ animal/month)

${ }^{3}$ Based on the average carcass dressing of $52.42 \%$. Sale value: $R \$ 59.29 / @$.

cimento de suplementos com $24 \%$ de PB no período de transição seca/águas apresentou retorno econômico, com redução de custos e conseqüente elevação no resultado econômico da suplementação neste período.

Conhecer as variáveis com maior peso na determinação dos resultados de cada sistema é de extrema importância, pois, ao identificar os itens de maior impacto econômico, evitam-se erros ou decisões que ocasionem grandesconseqüências ou até prejuízos na instalação do sistema escolhido (Peres et al., 2004).

Os indicadores econômicos foram avaliados quanto aos dias de suplementação necessários para o abate dos animais (DPA), permitindo avaliar o dispêndio total com suplementação e o benefício gerado pela antecipação na liberação de áreas de pastagem (Tabela 5).
Neste contexto, por meio da análise de sensibilidade, em função das possíveis variações nos valores de insumos e de venda do animal, observou-se o mesmo comportamento (Tabela 5), com superioridade para o suplemento com $24 \%$ de PB (Tabela 6).

Destaca-se que, em quaisquer alterações nos preços dos insumos e da arroba, o fornecimento de suplementos com 8 e 16\% de PB implicou retorno econômico negativo.

A lucratividade do sistema de produção é altamente dependente das variações de mercado, tanto para preços de aquisição de insumos quanto para venda de animais. Dessa forma, utilizando-se o processo de armazenagem, a aquisição de insumos em períodos de alta oferta e, conseqüentemente, o menor preço podem elevar de forma satisfatória a lucratividade do sistema (Detmann et al., 2004). 
Os valores de $\mathrm{pH}$ e as concentrações de amônia ruminal obtidos no experimento 2 são apresentados na Tabela 7 . Não foram observados efeitos $(\mathrm{P}>0,10)$ dos níveis de proteína sobre os valores de $\mathrm{pH}$. Os valores médios observados mantiveram-se acima do limite de 5,0 a 5,5 proposto por Hoover (1986) como inibitório à digestão da fibra.

O fornecimento de suplementos ricos em milho (amido) contribui para redução no pH (Zervoudakis et al., 2002b), podendo reduzir a atividade de bactérias celulolíticas, re sultando em decréscimo na digestibilidade e no consumo da forragem. No entanto, não foram encontrados efeitos dos tratamentos sobre o $\mathrm{pH}$ ruminal neste estudo.

$\mathrm{Na}$ literatura, são contraditórios os dados referentes à queda no $\mathrm{pH}$ e ao efeito prejudicial do amido sobre a digestão e o consumo de forragem (Karges et al., 1992). Evidencia-se, portanto, a existência de mecanismos adicionais envolvidos

Tabela 6 - Análise de sensibilidade, por animal, para o retorno bruto $(R \$)$, calculado em função do necessário para o alcance de $450 \mathrm{~kg}$ de PV, de acordo com variações nos valores comerciais de suplementos e venda de animais

Table 6 - Sensibility analysis per animal for crude income ( $R \$)$, calculated based on the time needed to reach $450 \mathrm{~kg}$ of body weight according to the values of supplements and sale of animals

\begin{tabular}{|c|c|c|c|c|}
\hline \multicolumn{2}{|c|}{$\begin{array}{l}\text { Variação } \\
\text { Variation }\end{array}$} & \multicolumn{3}{|c|}{$\begin{array}{c}\text { Nível de proteína (\%) } \\
\text { Protein level }(\%)\end{array}$} \\
\hline $\begin{array}{l}\text { Venda animais } \\
\text { Sale of animals }\end{array}$ & $\begin{array}{l}\text { Custo suplemento } \\
\text { Supplement cost }\end{array}$ & 8 & 16 & 24 \\
\hline $0 \%$ & $0 \%$ & $-45,31$ & $-10,02$ & 12,25 \\
\hline$+2,5 \%$ & $0 \%$ & $-45,72$ & $-9,64$ & 13,12 \\
\hline$+5,0 \%$ & $0 \%$ & $-46,13$ & $-9,26$ & 14,00 \\
\hline $0 \%$ & $-5,0 \%$ & $-43,91$ & $-8,50$ & 13,88 \\
\hline$+2,5 \%$ & $-5,0 \%$ & $-44,32$ & $-8,12$ & 14,76 \\
\hline$+5,0 \%$ & $-5,0 \%$ & $-44,73$ & $-7,74$ & 15,63 \\
\hline $0 \%$ & $-10,0 \%$ & $-42,52$ & $-6,97$ & 15,52 \\
\hline$+2,5 \%$ & $-10,0 \%$ & $-42,93$ & $-6,59$ & 16,39 \\
\hline$+5,0 \%$ & $-10,0 \%$ & $-43,33$ & $-6,21$ & 17,27 \\
\hline $0 \%$ & $-15,0 \%$ & $-41,12$ & $-5,45$ & 17,15 \\
\hline$+2,5 \%$ & $-15,0 \%$ & $-41,53$ & $-5,07$ & 18,03 \\
\hline$+5,0 \%$ & $-15,0 \%$ & $-41,94$ & $-4,69$ & 18,90 \\
\hline
\end{tabular}

na redução do consumo de forragem, uma vez que a queda de pH esteve mais relacionada ao nível de suplementação que à fonte suplementar (Caton \& Dhuyvetter, 1997).

A redução no consumo de forragem em animais recebendo suplementos energéticos pode ser atribuída a mudanças nas proporções relativas das populações de microrganismos no rúmen em função da competição por substratos, principalmente $\mathrm{N}$ (Olson et al., 1999).

A teoria com melhor fundamentação parece ser a da competição por substratos essenciais, principalmente nitrogênio, entre bactérias amilolíticas e celulolíticas, visto que o aumento na oferta de amido no rúmen favorece o crescimento da população de bactérias amilolíticas em detrimento às celulolíticas, pois o amido é fermentado muito mais rapidamente que as fibras (Dixon \& Stockdale, 1999), acarretando redução na taxa de fermentação da fibra com conseqüente redução no consumo.

A análise da concentração ruminal de $\mathrm{N}$-amoniacal $\left(\mathrm{N}-\mathrm{NH}_{3}\right)$ demonstrou efeito $(\mathrm{P}<0,10)$ entre os animais dos tratamentos com e sem suplementação. Adicionalmente, com o aumento dos teores de PB nos suplementos, houve incremento linear $(\mathrm{P}<0,10)$ da concentração de $\mathrm{N}^{-\mathrm{NH}_{3}}$. A média observada para o suplemento com $24,0 \%$ de $\mathrm{PB}$ foi superior $(\mathrm{P}<0,10)$ à dos demais tratamentos, provavelmente em razão da maior ingestão de proteína permitida pela seleção dos ingredientes disponíveis.

Os valores obtidos estiveram acima dos 5,0 $\mathrm{mg}$ de $\mathrm{N}-\mathrm{NH}_{3} / \mathrm{dL}$ de líquido ruminal sugeridos por Satter \& Slyter (1974) como não limitantes à fermentação microbiana, indicando que o teor de amônia ruminal não limitou a fermentação em nenhum tratamento.

Por outro lado, o nível de $\mathrm{N}-\mathrm{NH}_{3}$ nos bovinos que consumiram suplemento com apenas $8,0 \%$ de PB esteve aquém do mínimo de $10 \mathrm{mg} / \mathrm{dL}$ de líquido ruminal, considerado ótimo para adequada fermentação em condições tropicais (Leng, 1990), o qual foi observado para os suplementos contento 16,0 e $24,0 \%$ de PB.

Tabela 7 - Médias, coeficiente de variação (CV) e probabilidades (P) dos efeitos linear (L) e quadrático (Q) obtidas para pH e N-NH 3 ( $\mathrm{mg} / \mathrm{dL}$ de líquido ruminal) com os diferentes níveis de proteína

Table 7 - Means, coefficient of variation (CV) and level of probability $(P)$ of linear $(L)$ and quadratic $(Q)$ effects for ruminal $\mathrm{pH}$ and $\mathrm{NH} \mathrm{H}_{3} \mathrm{~N}(\mathrm{mg} / \mathrm{dL})$ of crossbred steers fed supplements with different crude protein levels

\begin{tabular}{|c|c|c|c|c|c|c|c|c|}
\hline \multirow[b]{2}{*}{ Item } & \multirow[b]{2}{*}{$\mathrm{MM}^{*}$} & \multicolumn{3}{|c|}{$\begin{array}{c}\text { Nível de proteína } \\
\text { Protein level }\end{array}$} & \multicolumn{3}{|c|}{$\begin{array}{l}\text { Valor } \mathrm{P}^{1} \\
P \text { value }\end{array}$} & \multirow[b]{2}{*}{$\mathrm{CV}(\%)$} \\
\hline & & 8,0 & 16,0 & 24,0 & $\begin{array}{l}\text { MM x suplementação } \\
\text { Mineral mix } x \text { supplement }\end{array}$ & $\mathrm{L}$ & Q & \\
\hline $\mathrm{pH}$ & 6,63 & 6,49 & 6,43 & 6,52 & 0,2500 & 0,8283 & 0,5619 & 3,11 \\
\hline $\mathrm{N}-\mathrm{NH}_{3}{ }^{2}$ & 6,69 & 8,41 & 10,69 & 12,92 & 0,0099 & 0,0139 & 0,9874 & 19,15 \\
\hline
\end{tabular}

${ }^{1} \mathrm{MM}$ vs suplementos, $\mathrm{L}$ e $\mathrm{Q}=$ efeitos linear e quadrático para níveis de PB nos suplementos, respectivamente; ${ }^{2} \hat{\mathrm{Y}}=6,1700+0,2817 \mathrm{NP}\left(\mathrm{r}^{2}=0,9998\right)$. ${ }^{1} \mathrm{C}$ vs $S$ - control (MM) vs. supplements, $L$ and $Q=$ linear and quadratic effects for different crude protein levels, respectively. 
Considerando o comportamento linear do desempenho dos animais (Tabela 3) e dos níveis de $\mathrm{N}-\mathrm{NH}_{3}$ (Tabela 7), em função dos níveis de $\mathrm{PB}$, pode-se inferir que o efeito positivo da suplementação protéica em bovinos sob pastejo durante o período chuvoso também foi maximizado pelos maiores níveis de $\mathrm{N}-\mathrm{NH}_{3}$ no ambiente ruminal. Dessa forma, este maior aporte de $\mathrm{N}$ propiciaria maximização da síntese de proteína microbiana, com conseqüências positivas sobre o consumo de nutrientes, a taxa degradação dos constituintes da parede celular e o desempenho animal.

\section{Conclusões}

O desempenho produtivo de bovinos sob pastejo durante o período de transição seca/águas éinfluenciado pelo nível de proteína bruta fornecido via suplementação.

Suplementos com baixos níveis de proteína (alimentos energéticos) podem ser antieconômicos, pois, quando fornecidos de forma exclusiva, apresentam potencial para ganho de peso menor que o da suplementação protéica.

O suplemento com $24,0 \%$ de proteína bruta resultou em melhor desempenho e em retorno econômico favorável nos animais terminados a pasto durante o período de transição seca/águas.

O fornecimento de $1,0 \mathrm{~kg}$ de suplemento para bovinos em pastejo não influenciou o $\mathrm{pH}$ do líquido ruminal, entretanto, os suplementos com maiores níveis protéicos proporcionaram maiores concentrações de amônia ruminal, tornando o ambiente ruminal mais propício ao crescimento microbiano.

\section{Literatura Citada}

BARBOSA, M.A.A.F.; NASCIMENTO JR., D.; CECATO, U. Desempenho de novilhos em capim tanzânia com diferentes ofertas de forragem. In: REUNIÃO ANUAL DA SOCIEDADE BRASILEIRA DE ZOOTECNIA, 38., 2005, Piracicaba. Anais... Piracicaba: Sociedade Brasileira de Zootecnia, 2001 (CD-ROM).

CATON, J.S.; DHUYVETTER, D.V. Influence of energy supplementation on grazing ruminants: requeriments and responses. Journal of Animal Science, v.75, p.533-542, 1997.

CHASE JR., C.C.; HIBBERD, C.A. Utilization of low quality native grass hay by beef cows fed increasing quantities of corn grain. Journal of Animal Science, v.65, p.557-566, 1987.

DETMANN, E.; PAULINO, M.F.; ZERVOUDAKIS, J.T. et al. Níveis de proteína bruta em suplementos múltiplos para terminação de novilhos mestiços em pastejo durante a época seca: desempenho produtivo e características de carcaça. Revista Brasileira de Zootecnia, v.33, n.1, p.169-180, 2004.

DETMANN, E.; PAULINO, M.F.; CECON, P.R. et al. Níveis de proteína em suplementos para terminação de bovinos em pastejo durante o período de transição seca/águas: consumo voluntário e trânsito de partículas Revista Brasileira de Zootecnia, v.34, n.4, p.1371-1379, 2005a.

DETMANN, E.; PAULINO, M.F.; VALADARES FILHO, S.C. et al. Níveis de proteína bruta em suplementos para terminação de bovinos em pastejo durante o período de transição seca/águas: Digestibilidade aparente e parâmetros do metabolismo ruminal e dos compostos nitrogenados Revista Brasileira de Zootecnia, v.34, n.4, p.1380-1391, 2005b.

DIXON, R.M.; STOCKDALE, C.R. Associative effects between forages and grains: consequences for feed utilization. Australian Journal of Agricultural Research, v.50, n.3, p.757-773, 1999.

EL-MEMARI NETO, A.C.; ZEOULA, L.M.; CECATO, U. et al. Suplementação de novilhos Nelore em pastejo de Brachiaria brizantha com diferentes níveis e fontes de concentrado. Revista Brasileira de Zootecnia, v.32, n.6, p.1945-1955, 2003 (supl. 2).

HOOVER, W.H. Chemical factors involved in ruminal fiber digestion. Journal of Dairy Science, v.69, n.10, p.27552766, 1986.

KARGES, K.K.; KLOPFENSTEIN T.J.; WLIKERSON, V.A. et al. Effects of ruminal degradable protein and escape protein supplements in steers grazing summer native range. Journal of Animal Science, v.70, n.6, p.1957-1964, 1992.

LENG, R.A. Factors affecting the utilization of "poor - quality" forages by ruminants particularly under tropical conditions. Nutrition Research and Review, v.3, n.3, p.277-303, 1990

McCOLLUM III, F.T.; HORN, G.W. Protein supplementation of grazing ruminants. Journal of Animal Science, v.67, p.304, 1989 (suppl. 1).

McMENIMAN, N.P. Methods of estimating intake of grazing animals. In: REUNIÃO ANUAL DA SOCIEDADE BRASILEIRA DE ZOOTECNIA, 34., 1997, Juiz de Fora. Anais... Juiz de Fora: Sociedade Brasileira de Zootecnia, 1997. p.131-168.

MERTENS, D.R. Gravimetric determination of amylase treated neutral detergent fiber in feeds with refluxing in beakers or crucibles: collaborative study. Journal of AOAC International, v. 85, n.6, p.1212-1240, 2002.

MINSON, D.J. Forage in ruminant nutrition. New York: Academic Press, 1990. 483p.

MORAES, E.H.K.; PAULINO, M.F; ZERVOUDSAKIS, J.T. et al. Avaliação qualitativa da pastagem diferida de Brachiaria decumbens stapf., sob pastejo, no período da seca, por intermédio de três métodos de amostragem. Revista Brasileira de Zootecnia, v.34, n.1, p.30-35, 2005.

MORAES, E.H.B.K; PAULINO, M.F.; FIGUEIREDO, D.M. et al. Desempenho de novilhos de corte submetidos a diferentes freqüências de suplementação no período das águas. In: REUNIÃO ANUAL DA SOCIEDADE BRASILEIRA DE ZOOTECNIA, 42., 2005, Goiânia. Anais... Goiânia: Sociedade Brasileira de Zootecnia, 2005 (CD-ROM).

OLSON, K.C.; COCHRAN, R.C.; JONES, T.J. et al. Effects of ruminal administration of supplemental degradable intake protein and starch on utilization of low-quality warm-season grass hay by beef steers. Journal of Animal Science, v.77, p.1016-1025, 1999.

PAULINO, M.F.; MACEDO, T.S; SALES, M.F.L. et al. Suplementação como estratégia de manejo das pastegens. In: VOLUMOSOS NA PRODUÇÃO DE RUMINANTES: VALOR ALIMENTÍCIO DE FORRAGENS, 2003, Jaboticabal. Anais... Jaboticabal: 2003. p.87-100.

PAULINO, M.F.; MORAES, E.H.B.K.; ZERVOUDAKIS, J.T. et al. Fontes de energia em suplementos múltiplos de autoregulação de consumo na recria de novilhos mestiços em pastagens de Brachiaria decumbens durante o período das águas. Revista Brasileira de Zootecnia, v.34, n.3, p.957962, 2005

PAULINO, M.F.; ZERVOUDAKIS, J.T.; MORAES, E.H.B.K et al. Bovinocultura de ciclo curto em pastagens. In: SIMPÓSIO DE PRODUCÃO DE GADO DE CORTE, 2., 2002, Viçosa, MG. Anais... Viçosa, MG: SIMCORTE, 2002. p.153-196.

PAULINO, M.F.; REHFELD, O.A.M.; RUAS, J.R.M. Alguns aspectos da suplementação de bovinos de corte em regime de 
pastagem durante a seca. Informe Agropecuário, v.8, n.89, p. 28-31, 1982 .

PERES, A.A.C.; SOUZA, P.M.; MALDONADO, H. Análise econômica de sistemas de produção a pasto para bovinos no município de Campos dos Goytacazes-RJ. Revista Brasileira de Zootecnia, v.33, n.6, p.1557-1563, 2004.

POPPI, D.P.; McLENNAN, S.R. Protein and energy utilization by ruminants at pasture. Journal of Animal Science, v.73, p.278-290, 1995.

REIS, R.A.; MELO, G.M.P; BERTIGAGLIA, L.M.A. et al. Suplementação de animais em pastagens: quantificação e custos In: SIMPÓSIO SOBRE MANEJO DA PAST AGEM, 22., 2005, Picacicaba. Anais... Piracicaba: Fundação de Estudos Agrários Luiz de Queiroz, 2005. p.279-352.

SATTER, L.D.; SLYTER, L.L. Effect of ammonia concentration on rumen microbial protein production in vitro. British Journal of Nutrition, v.32, p.199, 1974.

SNIFFEN, C.J.; O’CONNOR, J.D.; Van SOEST, P.J. et al. A net carbohydrate and system for evaluating cattle diets: II. Carbohydrate and protein availability. Journal of Animal Science, v.70, p.3562-3577, 1992

SILVA, D.J.; QUEIROZ, A.C. Análise de alimentos: métodos químicos e biológicos. 3.ed. Viçosa, MG: Universidade Federal de Viçosa, 2002. 165p.

SNIFFEN, C.J.; O'CONNOR, J.D.; Van SOEST, P.J. et al. A net carbohydrate and protein system for evaluating cattle diets: II. Carbohydrate and protein availability. Journal of Animal Science, v.70, p.3562-3577, 1992.
Van SOEST, P.J.; ROBERTSON, J.B. Analysis of forages and fibrous foods. Ithaca: Cornell University, 1985. 202p.

WEISS, W.P. Energy prediction equations for ruminant feeds. In: CORNELL NUTRITION CONFERENCE FOR FEED MANUFACTURERS, 61., 1999, Ithaca. Proceedings... Ithaca: Cornel University, 1999. p.176-185.

ZERVOUDAKIS, J.T.; PAULINO, M.F.; DETMANN, E. et al. Associação de diferentes fontes protéicas em suplementos múltiplos de auto-controle de consumo, para recria de novilhos em pastagens durante o período de transição águas-seca. In: REUNIÃO ANUAL DA SOCIEDADE BRASILEIRA DE ZOOTECNIA, 39., 2002, Recife. Anais... Recife: Sociedade Brasileira de Zootecnia, 2002a (CD-ROM).

ZERVOUDAKIS, J.T.; PAULINO, M.F.; DETMANN, E. et al. Desempenho de novilhas mestiças e parâmetros ruminais em novilhos, suplementados durante o período das águas. Revista Brasileira de Zootecnia, v.31, n.2, p.1050-1058, 2002b (supl.). 